\title{
Airborne spectral measurements of surface-atmosphere anisotropy for arctic sea ice and tundra
}

\author{
G. Thomas Arnold, ${ }^{1}$ Si-Chee Tsay, ${ }^{2}$, Michael D. King, ${ }^{2}$ \\ Jason $\mathrm{Y} . \mathrm{Li}^{1}{ }^{1}$ and Peter F. Soulen ${ }^{2,3}$ \\ Short title: Airborne measurements of arctic surface anisotropy \\ International Journal of Remote Sensing
}

(Submitted October 1999)

\footnotetext{
${ }^{1}$ SM\&A Corporation (East) Vienna, Va.

2 NASA Goddard Space Flight Center, Greenbelt, Maryland.

${ }^{3}$ Joint Center for Earth Systems Technology, University of Maryland Baltimore County, Baltimore, Maryland
} 


\author{
Authors - Mr. G. Thomas Arnold \\ SM\&A Corporation (East) \\ 2600 Park Tower Drive, Suite 1000 \\ Vienna, VA 22180 \\ (301) 614-6229 \\ (301) 614-6420 (fax) \\ arnold@climate.gsfc.nasa.gov (Internet) \\ Dr. Si-Chee Tsay \\ NASA Goddard Space Flight Center \\ Code 913 \\ Greenbelt, MD 20771 \\ (301) 614-6188 \\ Dr. Michael D. King \\ NASA Goddard Space Flight Center \\ Code 900 \\ Greenbelt, MD 20771 \\ (301) 614-5636 \\ Mr. Jason Y. Li \\ SM\&A Corporation (East) \\ 2600 Park Tower Drive, Suite 1000 \\ Vienna, VA 22180 \\ (301) 614-6230
}


Dr. Peter F. Soulen

NASA Goddard Space Flight Center

Code 913

Greenbelt, MD 20771

(301) 614-6203 


\title{
Airborne spectral measurements of surface-atmosphere anisotropy for arctic sea ice and tundra
}

\author{
G. Thomas Arnold (SM\&A Corp), Si-Chee Tsay (GSFC), Michael D. King (GSFC), \\ Jason Y. Li (SM\&A Corp), and Peter F. Soulen (UMBC/JCET)
}

\section{Popular Summary}

One of the factors affecting the Earth's climate is the reflection of sunlight from the Earth's surface back into space. The only practical way to measure reflected sunlight on a global scale is from satellite-based sensors. However such sensors typically measure the reflectance at only a single angle (usually from the surface directly below the satellite). This may or may not be representative of the true reflectance of the surface. To compute the true reflectance of a surface, the reflected sunlight from it in all directions must be known. The complete pattern of reflected sunlight from a surface is known as the bidirectional distribution function (BRDF). The more uniformly a surface reflects sunlight, the more representative the measured reflectance (such as by a satellite) is to the true reflectance. Thus for surfaces that do not reflect uniformly, knowing the BRDF for that surface is critical to knowing how to use the satellite sensor measurement to determine the true reflectance. In this paper we examine four common Arctic surfaces, snow-covered sea ice, melt-season sea ice, snow-covered tundra, and snow free tundra to determine their complete reflectance patterns and to determine how well a single reflectance measurement directly above the surface compares to the true reflectance of each surface. The reflectance measurements were obtained using an aircraft-based instrument called Cloud Absorption Radiometer during April 1992 and June 1995, and were done for several wavelengths of reflected sunlight. Polar plots of each measured wavelength showing the complete reflectance pattern of each surface are presented. The true reflectance for each surface is computed from this data and compared to the reflectance measurement directly above the surface. Reflectance above the snow surfaces most closely approximated the true reflectance, especially at the shortest wavelengths. Reflectance above the melt-season sea ice also fairly closely approximated the true reflectance, but slightly less so than the snow-covered surfaces. The snow-free tundra however was much different. Reflectance directly above the surface was as much as $50 \%$ less than the true reflectance. 


\begin{abstract}
Angular distributions of spectral reflectance for four common arctic surfaces: snow-covered sea ice, melt-season sea ice, snow-covered tundra, and tundra shortly after snowmelt were measured using an aircraft based, high angular resolution (1-degree) multispectral radiometer. Results indicate bidirectional reflectance is higher for snow-covered sea ice than melt-season sea ice at all wavelengths between 0.47 and $2.3 \mu \mathrm{m}$, with the difference increasing with wavelength. Bidirectional reflectance of snow-covered tundra is higher than for snow-free tundra for measurements less than $1.64 \mu \mathrm{m}$, with the difference decreasing with wavelength. Bidirectional reflectance patterns of all measured surfaces show maximum reflectance in the forward scattering direction of the principal plane, with identifiable specular reflection for the melt-season sea ice and snow-free tundra cases. The snow-free tundra had the most significant backscatter, and the melt-season sea ice the least. For sea ice, bidirectional reflectance changes due to snowmelt were more significant than differences among the different types of melt-season sea ice.

Also the spectral-hemispherical (plane) albedo of each measured arctic surface was computed. Comparing measured nadir reflectance to albedo for sea ice and snow-covered tundra shows albedo underestimated $5-40 \%$, with the largest bias at wavelengths beyond $1 \mu \mathrm{m}$. For snow-free tundra, nadir reflectance underestimates plane albedo by about $30-50 \%$.
\end{abstract}




\section{Introduction}

The interaction of solar radiation with various arctic surfaces is an important component of the arctic climate. A measure of this interaction is the surface bidirectional reflectance function (BRF). The full angular distribution of BRF for a given surface (at a particular solar incidence angle) is known as the bidirectional reflectance distribution function (BRDF). Knowledge of the BRDF for a surface gives a complete description of its reflectance. Remote sensing instruments typically have narrow fields of view, and measure only the reflected radiance at a single angle (thus only a small portion of the BRDF). Even the next generation satellites [King, 1999] will measure reflectance at a limited number of view angles. Thus proper interpretation of the remote sensing data will require knowledge of the BRDF of all surface types.

The Cloud Absorption Radiometer (CAR) [King et al., 1986] flying aboard the University of Washington C-131A aircraft has provided a convenient and efficient means of obtaining BRF data. CAR BRF data over the past decade have been collected for several surface types. BRF data collected during the Kuwait Oil Fire Smoke Experiment (KOFSE) over an oil fire generated smoke layer is described by King [1992]. Tsay et al. [1998] describe BRF data gathered in Brazil over cerrado, dense forest, and smoke over dense forest, during the Smoke Clouds and Radiation - Brazil experiment (SCAR-B). Additional BRF data for the Saudi Arabian desert, forested wet land (Great Dismal Swamp), and ocean water containing sunglint over the Atlantic Ocean and Persian Gulf have been discussed by Soulen et al. [1999]. In this work we present BRF data of four common arctic surfaces: snow-covered sea ice, melt-season sea ice, snow-covered tundra, and tundra shortly after snowmelt. The snow-covered sea ice and tundra data were collected as part of the arctic Lead Experiment (LEADEX), and the melt-season 
sea ice and tundra BRF data were collected during the Arctic Radiation Measurements in Column Atmosphere-Surface System (ARMCAS) experiment.

Several studies of sea ice reflective characteristics have been reported [Grenfell and Maykut, 1977; Grenfell and Perovich, 1984; Perovich et al., 1986; Allison et al., 1993; and DeAbreu et al., 1995]. These sea ice studies, using typically groundbased instrumentation in mostly diffuse light conditions (overcast sky), discuss sea ice characteristics and their spatial and temporal effects on both spectral and wavelength-integrated albedo. Highlighted in particular are the changes that occur with the onset of the melt-season. Prior to the melt-season (usually about late May in the arctic), sea ice albedo is mostly a function of the optical properties of the "dry" snow cover that overlies the sea ice. With the onset of the melt-season, however, the snow cover quickly begins to melt. Sea ice albedo then becomes a function of the sea ice characteristics such as brine and bubble concentrations, ice temperature, and ice thickness, coupled with the local meteorology (freeze-thaw cycles). The result is increased spatial variability and reduced reflectivity at all wavelengths (especially above about $1 \mu \mathrm{m}$ where nearly all the incident solar radiation is absorbed).

Direct application of these sea ice studies to remote sensing data (due to the characteristics of the remote sensing data) have heretofore been limited. To make the limited view angle remote sensing data more directly applicable, knowledge of the BRF at all azimuthal and polar viewing angles is needed. BRF of snow has been addressed by several studies [Dirmhirn and Eaton, 1975; Kuhn, 1985; Steffen, 1987; Dozier et al., 1988; Hall et al., 1993; and Warren et al., 1998 (includes a comprehensive review of factors affecting the BRDF of snow)], but BRF of sea ice has been limited. Perovich [1991] found that at azimuth angles $0^{\circ}$ and $90^{\circ}$ from solar incidence, reflectance of a refrozen melt pond and young sea ice 
$0.2 \mathrm{~m}$ thick was relatively constant. Reflectance at zenith angles out to about $50^{\circ}$ was relatively constant, but increased sharply for larger polar angles. Perovich [1994] reports that for sea ice progressing from cold dry snow-covered (pre-melt) conditions through various stages of melting, BRF data in the wavelength range $0.4-1.0 \mu \mathrm{m}$ at a polar angle of $30^{\circ}$ is nearly azimuthally isotropic, but has a notable specular peak at $60^{\circ}$. Both of these studies, however, were limited in wavelength range and number of polar angles measured.

BRF studies of arctic tundra have also been limited. Recently, however, Vierling et al. [1997] and Eck et al. [1997] have reported results of ground-based BRF measurements taken during ARMCAS. They used the portable apparatus for instrument rapid acquisition of bidirectional observations of the land and atmosphere (PARABOLA) to measure the BRDF of three types of arctic tundra: wet sedge (northernmost tundra), non-woody tussock tundra, and woody tussock tundra. The PARABOLA measures the nearly complete BRDF of three wavelength regions, but with an instantaneous field-of-view of $15^{\circ}$. Eck et al. [1997] report total albedo computed from the PARABOLA measurements to compare within $7.5 \%$ of pyranometer based measurements. Vierling et al. [1997] discuss how to use the BRDF measurements to differentiate between the three types of arctic tundra.

In this paper the BRF data for each arctic surface are also used to compute surface hemispherical albedo. Surface hemispherical albedo represents the "true" albedo for a given surface. However, nadir reflectance (often the parameter measured from an aircraft or satellite) is sometimes used as a surrogate [Barnsley et al., 1994]. Perovich [1994] reports that for sea ice evolving through the different melting stages, the spectral shape of nadir reflectance for wavelengths from 0.4 to $1.0 \mu \mathrm{m}$ is similar to the spectral albedo shape. The ratio of these two 
parameters was high (near 1.0) for the dry snow but, as melting progressed, the ratio decreased, especially at longer wavelengths. Similar comparisons have been done from our measurements and described below.

In the next section, we quantitatively define surface bidirectional reflectance (as used in this work) and how hemispherical albedo is computed. In section 3, the instrumentation and data strategy are summarized, followed by discussion in section 4 of each measured surface spectral anisotropy and hemispherical albedo computation. A summary of this work is given in section 5 .

\section{Definitions}

Following Tsay et al. [1998], we characterize the surface anisotropy from spectral measurements following the definition of bidirectional reflection function (BRF, $R_{\lambda}$ ) found in van de Hulst [1980] and given by

$$
R_{\lambda}\left(\theta, \theta_{0}, \phi\right)=\frac{\pi I_{\lambda}\left(\theta, \theta_{0}, \phi\right)}{\mu_{0} F_{\lambda}},
$$

where $\theta$ and $\theta_{0}$ are the viewing and illumination zenith angles respectively; $\phi$ is the azimuth angle between the viewing and illumination directions; $\mu_{0}=\cos \theta_{0}$; $F_{\lambda}$ is the collimated irradiance; and $I_{\lambda}$ is the corresponding reflected radiance. The collimated irradiance $F_{\lambda}$ is computed by weighting the solar flux at the top of the atmosphere with the spectral response function of each band, taking into account the eccentricity of the earth's orbit around the sun. (Note: this definition does not account for atmospheric effects, but for most CAR channels this should be relatively small - see section 3 for additional details.)

Similarly for the spectral albedo, $r_{\nu}$ radiance received by the detector from all viewing directions/solid angles are integrated (summed up for all IFOVs). Using Eq. (1), the spectral albedo is given by 


$$
\begin{aligned}
r_{\lambda}\left(\theta_{0}\right) & =\frac{1}{\pi} \int_{0}^{2 \pi} \int_{0}^{\pi / 2} R_{\lambda}\left(\theta, \theta_{0}, \phi\right) \cos \theta \sin \theta d \theta d \phi, \\
& \cong \frac{1}{\mu_{0} F_{\lambda}}\left[\sum_{i=1}^{M} \sum_{j=1}^{N} I_{\lambda}\left(\theta_{i}, \theta_{0}, \phi_{j}\right) \cos \theta_{i} \sin \theta_{i} \Delta \theta_{i} \Delta \phi_{j}\right],
\end{aligned}
$$

where $(i, j)$ are the indices of $(\theta, \phi)$ for discretization $(M, N$ terms) respectively, over the hemisphere.

\section{Instrumentation and data collection}

During LEADEX and ARMCAS, measurements of surface-atmosphere bidirectional reflectance were acquired by using a multispectral scanning radiometer - the Cloud Absorption Radiometer (CAR), which was designed and built at NASA Goddard Space Flight Center [cf. King et al., 1986 for details]. The CAR was mounted in the nose of the University of Washington's C-131A research aircraft, providing radiometric measurements at 13 discrete wavelengths between 0.3 and $2.3 \mu \mathrm{m}$. The first 7 channels are continuously recorded, whereas channels 8 through 13 are located in a filter-wheel that can be locked at a particular channel or manually or automatically rotated to measure a new wavelength interval after a preset number of scans. The wavelength location of each channel was selected to minimize atmospheric absorption effects (except for the UV-B channel where it is desired). The visible channel reflectance is weakly reduced by ozone absorption, and well as by aerosol and Rayleigh scattering. Aerosol effects should be small due to the relatively clean arctic air. The shortwave-infrared channel reflectance can be reduced by $2-8 \%$ due to water vapor and trace gas absorption.

Viewing with an IFOV of $1^{\circ}$, the CAR scans in a vertical plane on the right hand side of the aircraft from $5^{\circ}$ before zenith to $5^{\circ}$ past nadir ( $190^{\circ}$ aperture), thereby permitting observations of both the zenith and nadir radiances to be obtained with as much as a $5^{\circ}$ aircraft roll, an angle that is measured simultane- 
ously with a gyroscope aboard the aircraft. Table 1 summarizes the CAR specifications.

The C-131A flew at an average speed of about $80 \mathrm{~m} \mathrm{~s}-1$ in a circle with a minimum diameter of about $3 \mathrm{~km}$, at a comfortable roll angle of $20^{\circ}$ in about two minutes. At an altitude of $600 \mathrm{~m}$ above the targeted surface area and $1^{\circ}$ IFOV, the pixel resolution is about $10 \mathrm{~m}$ at nadir and about $270 \mathrm{~m}$ at an $80^{\circ}$ viewing angle from the CAR (see King [1992] and Tsay et al. [1998] for additional details).

\section{Results from observations}

The assumption of homogeneity of the targeted surface area is fundamental to properly reconstructing the bidirectional reflectance from CAR measurements. Thus targets were carefully selected to be as homogeneous as possible. During ARMCAS and LEADEX, eight spectral BRF data sets were obtained and analyzed. The location of each BRF study on the north slope of Alaska and nearby Arctic Ocean is shown in figure 1, which further designates the precise location by assigning a letter from A-H. These eight studies have been categorized according to one of four types of surfaces measured: (i) snow-covered sea ice, (ii) melt-season sea ice, (iii) snow-covered tundra, or (iv) snow-free tundra. Two snow-covered sea ice BRF studies (A and B in figure 1) were acquired over the Beaufort Sea under nearly clear-sky conditions, from 20:50 to 20:57 and 21:15 to 21:24 UTC on April 7, 1992. Three melt-season sea ice BRFs (C, D, and E) were also acquired over the Beaufort Sea under nearly clear-sky conditions, from 00:44 to $00: 55$ UTC on June 6,1995 , and from $18: 34$ to $19: 39$ and 20:58 to $21: 19$ UTC on June 8, 1995. One snow-covered tundra BRF (F) was acquired just south of Prudhoe Bay, with nearly clear sky above (only some patchy thin cirrus), from 23:38 to 23:43 UTC on April 7,1992. Finally, two snow-free tundra cases (G and 
H) were acquired south of Prudhoe Bay, with nearly clear sky above, from 06:37 to 06:48 and from 06:57 to 07:09 UTC on June 12, 1995.

\subsection{Snow-covered sea ice (April 1995)}

Two three-orbit BRFs under clear sky conditions were conducted over snowcovered multi-year sea ice (locations A and B in figure 1). The solar zenith angle $\theta_{0}$ for the two cases varied from $65.14^{\circ}-65.26^{\circ}$ and $65.22^{\circ}-65.35^{\circ}$, respectively (cf. table 2). Figure 2a shows a representative photograph of snow-covered sea ice taken in the area where these BRF measurements were obtained. Due to the optically thick snow cover, the optical effects of the underlying sea ice is limited. Variations in surface reflectance are primarily due to shadowing caused by the relatively low sun angle and irregularities in the surface (pressure ridges). These effects are relatively small. The CAR filter-wheel channel was locked at $1.64 \mu \mathrm{m}$ for 1 orbit in BRF A and for one orbit in B at $2.20 \mu \mathrm{m}$.

Figure 3 contains the spectral BRF for each measured CAR channel over the snow-covered sea ice (since the BRF plots for A and B were similar, only those from $\mathrm{A}$ are shown here except for the $2.2 \mu \mathrm{m}$ plot). In these and all other polar plots, zenith angle is represented as radial distance from the center, and azimuth angle as length of the arc on the respective zenith circle. The principal plane resides in the $0^{\circ}-180^{\circ}$ azimuthal plane with the sun located in the $0^{\circ}$ azimuth direction. With this definition, the upper half circle represents forward scattering and the lower half represents backscattering, with the anti-solar direction at $\theta_{0} \approx 65^{\circ}$, denoted by the white spot in the upper left plot of figure 3a.

The BRF pattern in figure 3 shows reflectance minimized in the region around nadir and increasing going out from nadir, particularly in the solar and anti-solar directions. The strongest peak is in the forward scattering direction (specular reflection), while there is a diffuse and weaker peak in the backscatter- 
ing direction. Interestingly, while the plot suggests a high degree of symmetry, reflectance mid-way between the solar and anti-solar directions is notably lower on the right than on the left in the dataset. The cause of this asymmetry is not clear.

To investigate further the detailed angular distribution of BRF, figure $4 a$ shows the spectral dependence of the reflection function along the principal plane. Except for the forward and backscattering regions near the limb, the plots for each band are otherwise fairly flat, representing a nearly Lambertian reflectance of snow-covered sea ice away from the specular reflectance direction.

\subsection{Melt-season sea ice (June 1995)}

The three melt-season sea ice cases were obtained in different geographical regions (locations $C, D$, and $E$ in figure 1) to compare different types of sea ice. BRF C was 4 orbits, D was 35 orbits, and $\mathrm{E}$ was 10 orbits. Solar zenith angles varied from $54.51^{\circ}-55.26^{\circ}, 53.28^{\circ}-57.69^{\circ}$, and $48.93^{\circ}-49.45^{\circ}$ respectively, for $C, D$, and E. The filter-wheel was locked at $1.64 \mu \mathrm{m}$ for 2,13 , and 4 orbits respectively, for C, D and E, and for 1,9, and 4 orbits at $2.2 \mu \mathrm{m}$. A photo of the melt-season sea ice (from June 8 ) is shown in figure $2 b$. The BRF from $C$ and $E$ were both of shorefast ice but from different parts of the coastline. (Both are likely young sea ice and somewhat surprisingly had fewer open leads than D). According to flight notes, the surface in $E$ showed no evidence of open leads or melt ponds at all (although a few ground spots were noted due to shallowness of the sea in that area). Much of the variability of the surface is likely due to melting and refreezing and varying thickness of the ice. As compared to snow-covered sea ice, surface characteristics of melt-season sea ice show much more variability, particularly at shorter wavelengths. 
Data for BRFs C, D, and E are listed in table 2, and the BRF plot from D is presented in figure 5 ( $C$ and $E$ are not shown but show similar features). The melt-season BRFs, like the snow-covered sea ice BRFs, show pronounced maxima in the forward scattering direction, and secondary maxima in the backscattering direction (though less apparent than for the snow-covered sea ice cases). Unlike the snow-covered sea ice, however, they show a distinct specular reflectance (sunglint) just to the right of the solar principal plane and at an angle from nadir equivalent to the solar zenith angle (slightly offset from the principal plane due to the aircraft pitch). The most important difference though is that the reflectance values of all the CAR bands for the melt-season cases are lower than for the snow-covered sea ice. This is most pronounced for the 1.6 and $2.1 \mu \mathrm{m}$ channels. The melt-season sea ice surface for these channels is absorbing nearly all of the incident sunlight. The principal plane plots in figure $4 \mathrm{~b}$ show reflectance of $1-2 \%$ in these bands, considerably lower than the snow-covered sea ice in figure 4a.

\subsection{Snow-covered tundra (April 1992)}

Following the two snow-covered sea ice BRFs (locations A and B), the C131A flew a two-orbit BRF pattern over snow-covered tundra to the south of Prudhoe Bay ( $\mathrm{F}$ in figure 1). The solar zenith angle varied from $65.14^{\circ}-65.35^{\circ}$ (table 2), and the filter-wheel was locked at $1.64 \mu \mathrm{m}$ for one orbit. A photo of snow-covered tundra is shown in figure $2 c$, with the Trans-Alaska Pipeline clearly evident in this photo. Figure 6 illustrates the two-orbit average BRF for this case, which again shows maximum reflectance in the forward scattering direction with some evidence for a secondary backscattering maximum, though less apparent than for snow-covered sea ice. The cause of the asymmetry, the minima in reflectance on the left-hand side of the circle is not clear. Reflectance values are generally slightly less than the snow-covered sea ice cases on this day, 
but are still quite high, even at $1.6 \mu \mathrm{m}$. A plot of the principal plane data is given in figure 7a. Snow covered tundra is quite Lambertian except for the forward scattering (specular reflectance) direction.

\subsection{Snow-free tundra (June 1995)}

Two BRF studies ( 5 orbits each) were conducted over the tundra south of Prudhoe Bay on June 12, 1995 (G and H in figure 1). These were "midnight sun" flights (solar zenith varied from $80.63^{\circ}-81.23^{\circ}$ and $82.00^{\circ}-82.61^{\circ}$, respectively). The filter-wheel was locked at $1.64 \mu \mathrm{m}$ for 3 and 2 orbits, respectively for $G$ and $H$ and for 1 and 2 orbits, respectively, for $2.1 \mu \mathrm{m}$. The tundra vegetation common to this part of the north slope is senescent wet sedge (little photosynthesis since snow cover has just melted) [Vierling et al., 1997]. Figure 1d shows a closeup photograph of this type of tundra surface. Though not apparent in this photograph the wet sedge was in many places partially submerged. The BRF plot in figure 8 (from $G$ ) depicts a fairly symmetric reflectance pattern for each case, with a fairly narrow maximum in the forward scattering direction (probably specular reflection due to the water in the tundra) and a broader (and higher for bands $0.87 \mu \mathrm{m}$ and longer) backscattering pattern. The plot is similar in appearance to the Brazilian cerrado (savannah) case described by Tsay et al. [1998], though with a much lower sun angle here. Note the relatively low reflectance in the nadir direction at all wavelengths. The principal plane plot for $G$ is shown in figure $7 \mathrm{~b}$.

\subsection{Spectral Albedo}

The spectral BRF measurements obtained by the CAR contain very fine angular resolution (i.e., $M=90$ samples in $\theta$ and $N \approx 200$ in $\phi, c f$. table 1 ) which produces virtually no computational error in discretizing the integral. By using Eq. 
(2), it is straightforward to compute the spectral-hemispherical albedo for the sea ice and tundra surfaces. The results for each of the sea ice and tundra cases are listed in tables 2 and 3, respectively. For each BRF case, columns 1 and 2 in each table lists the central wavelength and bandwidth characteristics of each CAR channel (note the change in channel 1 between 1992 and 1995). Column 3 lists the corresponding solar flux computed by weighting the solar flux at the top of the atmosphere with the spectral response function of each channel. The solar fluxes vary slightly from case to case due to the eccentricity of the earth's orbit about the sun. In column 4 , the solar zenith angle varies less than $2^{\circ}$ for all but one BRDF case (the 35 circle average of location $\mathrm{D} \sim 4.4^{\circ}$ ). Thus change in solar zenith angle does not contribute significantly to the variation in the computed spectral albedo (column 5). This variation is due largely to surface inhomogeneity. Column 6 lists the average reflectance value and variation at nadir for each BRF study, for comparison to the spectral albedo.

Generally for sea ice cases, the spectral albedo values in table 2 are consistent within a season, but show important differences when comparing the snowcovered sea ice to the melt-season sea ice, particularly for the longer wavelengths. This can easily be seen in the plot of hemispherical albedo as a function of wavelength in figure 9a. The data suggest separate curves for the two sea ice types. The difference in the curves is about $10 \%$ at $0.67 \mu \mathrm{m}$, increasing substantially with wavelength becoming about a factor of 2 at $1.03 \mu \mathrm{m}$, to a factor of 6 or more at $1.64 \mu \mathrm{m}$. Also shown in table 2 , the greater variability of the melt-season sea ice albedo at the shortest wavelength is indicative of a more variable surface (open leads, melt ponds, various types of bare ice, etc.) at this time of year.

Nadir reflectance values as a function of wavelength are presented in figure $9 \mathrm{~b}$ for each of the sea ice cases, with the corresponding ratio of nadir reflectance 
to albedo shown in figure 9c. Similar to the conclusion of Perovich, [1994], the plots of hemispherical albedo and nadir reflectance as a function of wavelength (figure $9 \mathrm{a}$ and $9 \mathrm{~b}$ ) have nearly the same spectral shape. Comparing the albedo of sea ice to the nadir reflectance (figure 9c), often used as a surrogate for surface albedo in climate models, yields two conclusions. First, at essentially all CAR wavelengths, the nadir snow-covered sea ice reflectance is a better surrogate for albedo than the melt-season sea ice albedo. Second, for both sea ice types, differences between hemispherical albedo and nadir reflectance exceed $10 \%$ only for CAR wavelengths greater than about $1 \mu \mathrm{m}$ (differences can be as much as $45 \%$ ).

Shown also in figures $9 a$ and $b$ is the effect on the data of applying an atmospheric correction for Rayleigh scattering and ozone absorption (dashed lines). Perovich (1994) and many others have shown that the albedo and nadir values for ice and snow surfaces should continue to approach unity as the wavelength decreases. Clearly the uncorrected reflectance of CAR channels 1 $(0.47$ or $0.50 \mu \mathrm{m})$ and $2(0.67 \mu \mathrm{m})$ show just the opposite effect. Thus a simple correction for Rayleigh scattering and ozone absorption (aerosol absorption is assumed to be small in the clean arctic air) is applied to the data from BRFs A,D, $F$, and $G$ and plotted as dashed lines in figures $9 a$ and $b$. This results in a more realistic shape to the curves. Note, however, that this is only a first order atmospheric correction; a more thorough atmospheric correction is left for future work.

Table 3 lists the spectral albedo and nadir reflectance values for the tundra cases. The snow-covered tundra albedos are slightly smaller than the snowcovered sea ice albedos at all wavelengths [cf. table 2]. Possible causes of this bias include age differences of the snow, temperature differences (degree of wetness of snow), contamination, and the effects due to underlying differences in surface reflectance (function of snow depth). Grenfell et al. [1984] discuss these 
types of effects in further detail. Since no samples were collected of the snow in either case, it is not possible to determine the relative role of each of these effects. The difference in snow-covered tundra albedo as compared the snow-free tundra, however, is much more apparent. The snow-covered tundra albedo values are much higher than the snow-free tundra albedos at all visible wavelengths, but this difference decreases with increasing wavelength, and actually reverses at $1.64 \mu \mathrm{m}$ [cf. figure 9a].

Comparison of the hemispheric albedo of the snow-covered tundra to the measured nadir reflectance, similar to the sea ice cases, indicates only a small underestimate of the true albedo for wavelengths less than about $1 \mu \mathrm{m}$. Differences can be as much as $40 \%$ for observations above $1 \mu \mathrm{m}$. For the snow-free tundra, however, the underestimate is much greater [cf. figure 9c]. The underestimate ranges from about $30-50 \%$ and, unlike sea ice, the largest differences occur at the shortest wavelengths.

\section{Summary}

An important part of a successful effort to monitor the Earth's climate in the EOS era is the proper treatment of the sun's interaction with each type of Earth surface. To accurately interpret satellite measurements of top-of-the-atmosphere radiance, it is necessary to know the bidirectional reflectance function of each Earth surface. Thus the radiative effects of natural surfaces should be taken into account for remote sensing of aerosols and clouds, and also accurate surface hemispherical albedos can be determined for input to global climate models.

During the LEADEX and ARMCAS field experiments, surface spectral bidirectional reflectance of sea ice and tundra for both snow-covered (pre-melt) and melt conditions were measured using the Cloud Absorption Radiometer (CAR). Snow-covered conditions for sea ice and tundra were monitored on April 7, 1992. 
Sea ice in melt conditions was monitored on June 5 and 8, 1995, and snow free tundra on June 12,1995. Despite contamination of the CAR data due to Rayleigh scattering and minor gaseous absorption (aerosol scattering was assumed to be small), results show distinct spectral characteristics for all types of surfaces presented here, particularly the seasonal bidirectional reflectance changes in sea ice and tundra surfaces. In all cases sea ice reflectivity decreases with the onset of the melt-season, with the degree of difference increasing with wavelength. Reflectivity of snow-covered tundra also decreased following snow-cover melt for CAR channels below $1.64 \mu \mathrm{m}$, but actually increased by a factor of two at 1.64 $\mu \mathrm{m}$. In addition, detailed measurements of the angular distribution of spectral reflectance were used to compute hemispherical albedos for each surface. For sea ice and snow-covered tundra, the CAR data indicate the surface spectral anisotropy only becomes significant at wavelengths greater than about $1 \mu \mathrm{m}$. Snowfree tundra, on the other hand, exhibits large surface spectral anisotropy at all wavelengths, with the greatest anisotropy at the shortest CAR wavelengths $(\sim 0.47 \mu \mathrm{m})$. Underestimates of the true albedo ranged from $30-50 \%$ when using nadir reflectance as a proxy for hemispherical albedo.

The CAR measurements, combined with boundary layer aircraft measurements of aerosol physical properties and other co-located observations, form an unprecedented data set that is expected to greatly facilitate developing more realistic radiative transfer models in the future. All CAR data from both the ARMCAS and LEADEX field experiments have been processed to level-1b (calibrated and geo-located radiance). Information on where and how to obtain CAR data from these and other field experiments (including all BRF polar plots), as well as browse images, a CAR data user's guide, and software for unpacking and interpreting CAR data, may be found on the World Wide Web at 
http://ltpwww.gsfc.nasa.gov/CAR.

Acknowledgments. The authors are especially grateful to Prof. P. V. Hobbs and all of the University of Washington personnel for helping to make these complex field projects and data collection a success. This research was supported by funding provided by the MODIS Science Team and NASA's Radiation Science Program. The University of Washington research flights during LEADEX were supported by the National Science Foundation under Grant DPP9116371. 


\section{References}

Allison, I., Brandt, R. E., and Warren, S. G., 1993, East Antarctic sea ice: albedo, thickness distribution, and snow cover, J. Geophys. Res., 98, 12417-12429.

Barnsley, M. J., Strahler, A. H., Morris, K. P., and Muller J. P., 1994, Sampling the surface bidirectional reflectance distribution function (BRDF): 1. Evaluation of current and future satellite sensors, Remote Sens. Rev., 8, 271-311.

DeAbreu, R. A., Barber, D. G., Misurak, K., and LeDrew, E. F., 1995, Spectral albedo of snow-covered first-year and multi-year sea ice during spring melt, Ann. Glaciol., 21, 337-342.

Dirmhirn, I., and Eaton, F. D., 1975, Some characteristics of the albedo of snow, J. Appl. Meteorol., 14, 375-379.

Dozier, J., Davis, R. E., Chang, A. T., and Brown, K., 1988, The spectral bidirectional reflectance of snow, Proceedings of the $4^{\text {th }}$ International Colloqium on Spectral Signatures of Objects in Remote Sensing, Eur. Space Agency Spec. Publ., ESA SP-287, 87-92.

Eck, T. F., Deering, D. W., and Vierling, L. A., 1997, Arctic tundra albedo and its estimation from spectral hemispheric reflectance, Int. J. Remote Sens., 18, 3535-3549.

Grenfell, T. C., and Maykut, G. A., 1977, The optical properties of ice and snow in the Artic Basin, J. Glaciol., 18, 445-463.

Grenfell, T. C., and Perovich, D. K., 1984, Spectral albedo of sea ice and incident solar irradiance in the southern Beaufort Sea, J. Geophys. Res., 89, 3573-3580.

Grenfell, T. C., Warren, S. G., and Mullen, P.C., 1994, Reflection of solar radiation by the Antarctic snow surface at ultraviolet, visible and near-infrared wavelengths, J. Geophys. Res., 99, 18669-18684.

Hall, D. K., Foster, J. L., Irons, J. R., and Dabney, P. W., 1993, Airborne bidirec- 
tional radiances of snow-covered surfaces in Montana, U.S.A., Ann. Glaciol, $17,35-40$.

King, M. D., Strange, M. G., Leone P., and Blaine, L. R., 1986, Multiwavelength scanning radiometer for airborne measurements of scattered radiation within clouds, J. Atmos. Oceanic Tech., 3, 513-522.

King, M. D., Ed., 1999, EOS Science Plan: The State of Science in the EOS Program, NASA Report NP-1998-12-069-GSFC, Goddard Space Flight Center, Greenbelt, MD, 397 pp.

King, M. D., 1992, Directional and spectral reflectance of the Kuwait Oil-Fire smoke, J. Geophys. Res., 97, 14545-14549.

Kuhn, M., 1985, Bidirectional reflectance of polar and alpine snow surfaces, Ann. Glaciol., 6, 2164-2167.

Perovich, D. K., Maykut, G. A., and Grenfell, T. C., 1986, Optical properties of ice and snow in the polar oceans. I: observations, Ocean Optics 8, Proc. SPIE Int. Soc. Opt. Eng., 637, 232-241.

Perovich, D. K., 1991, Seasonal changes in sea ice optical properties during fall freeze-up, Cold Reg. Sci. Technol., 19, 261-273.

Perovich, D. K., 1994, Light reflection from sea ice during the onset of melt, $J$. Geophys. Res., 99, 3351-3359.

Soulen, P. F., King, M. D., Tsay, S., Arnold, G. T., and Li, J. Y., Airborne spectral measurements of surface anisotropy during SCAR-A, Kuwait oil-fire, and TARFOX experiments, submitted to J. Geophys. Res.

Stefan, K., 1987,Bidirectional reflectance of snow at 500-600 nm, in large scale effects of seasonal snowcover, IAHS Publ., 166, 415-425.

Tsay, S. C., King, M. D., Arnold, G. T., and Li, J. Y., 1998, Airborne spectral measurements of surface anisotropy during SCAR-B, J. Geophys. Res., 103, 31943- 
31953.

van de Hulst, H. C., 1980, Multiple Light Scattering: Tables, Formulas, and Applications, 739 pp., Academic Press.

Vierling, L. A., Deering, D. W., and Eck, T. F., 1997, Differences in arctic tundra vegetation type and phenology as seen using bidirectional radiometry in the early growing season, Remote Sens. Environ., 60, 71-82.

Warren, S. G., Brandt, R. E., and Hinton, P. O., 1998, Effect of surface roughness on bidirectional reflectance of Antarctic snow, J. Geophys. Res., 103, 2578925807. 
Table 1. Cloud Absorption Radiometer specifications during field campaigns.

\begin{tabular}{ll}
\hline Platform & University of Washington C-131A aircraft \\
Ground speed & $80 \mathrm{~m} \mathrm{~s}^{-1}$ (nominal) \\
Total field of view & $190^{\circ}$ \\
Instantaneous field of view & $17.5 \mathrm{mrad}\left(1^{\circ}\right)$ \\
Pixels per scan line & 395 \\
Scan rate & 100 scan lines per minute \\
Spectral channels & $13(7$ continuously sampled and 6 in filter wheel) \\
Spectral range & $0.472(0.503)-2.303 \mu \mathrm{m}$ \\
Data system & 8 channels @ 10 bits \\
Calibration & Integrating sphere on the ground \\
\hline
\end{tabular}


Table 2. Computed spectral albedo and measured nadir reflectance for snowcovered sea ice (A-B) and melt-season sea ice (C-E). Uncertainties do not include possible errors in calibration.

\begin{tabular}{|c|c|c|c|c|c|}
\hline $\begin{array}{c}\text { Central wave- } \\
\text { length }(\mu \mathrm{m})\end{array}$ & $\begin{array}{c}\text { Bandwidth } \\
(\mu \mathrm{m})\end{array}$ & $\begin{array}{c}\text { Solar flux } \\
\left(\mathrm{W} \mathrm{m}^{-2} \mathrm{um}^{-1}\right)\end{array}$ & Solar zenith angle & Albedo & Nadir reflectance \\
\hline \multicolumn{6}{|c|}{ (A) Snow-covered sea ice (April 7, 1992) } \\
\hline 0.503 & 0.016 & 1901.7 & $65.14^{\circ}-65.26^{\circ}$ & $0.737 \pm 0.0040$ & $0.680 \pm 0.0262$ \\
\hline 0.673 & 0.020 & 1523.5 & $65.14^{\circ}-65.26^{\circ}$ & $0.770 \pm 0.0034$ & $0.718 \pm 0.0292$ \\
\hline 0.754 & 0.019 & 1281.1 & $65.14^{\circ}-65.26^{\circ}$ & $0.818 \pm 0.0029$ & $0.776 \pm 0.0315$ \\
\hline 0.866 & 0.020 & 947.85 & $65.14^{\circ}-65.26^{\circ}$ & $0.782 \pm 0.0012$ & $0.720 \pm 0.0286$ \\
\hline 1.031 & 0.020 & 706.75 & $65.14^{\circ}-65.26^{\circ}$ & $0.710 \pm 0.0036$ & $0.627 \pm 0.0264$ \\
\hline 1.220 & 0.021 & 497.66 & $65.14^{\circ}-65.26^{\circ}$ & $0.506 \pm 0.0060$ & $0.422 \pm 0.0221$ \\
\hline 1.270 & 0.020 & 410.52 & $65.14^{\circ}-65.26^{\circ}$ & $0.408 \pm 0.0058$ & $0.343 \pm 0.0187$ \\
\hline 1.640 & 0.041 & 232.27 & $65.20^{\circ}-65.26^{\circ}$ & 0.196 & $0.134 \pm 0.0144$ \\
\hline \multicolumn{6}{|c|}{ (B) Snow-covered sea ice (April 7, 1992) } \\
\hline 0.503 & 0.016 & 1901.7 & $65.22^{\circ}-65.35^{\circ}$ & $0.739 \pm 0.0010$ & $0.686 \pm 0.0127$ \\
\hline 0.673 & 0.020 & 1523.5 & $65.22^{\circ}-65.35^{\circ}$ & $0.774 \pm 0.0016$ & $0.728 \pm 0.0164$ \\
\hline 0.754 & 0.019 & 1281.1 & $65.22^{\circ}-65.35^{\circ}$ & $0.823 \pm 0.0020$ & $0.788 \pm 0.0176$ \\
\hline 0.866 & 0.020 & 947.85 & $65.22^{\circ}-65.35^{\circ}$ & $0.784 \pm 0.0013$ & $0.730 \pm 0.0168$ \\
\hline 1.031 & 0.020 & 706.75 & $65.22^{\circ}-65.35^{\circ}$ & $0.704 \pm 0.0029$ & $0.630 \pm 0.0186$ \\
\hline 1.220 & 0.021 & 497.66 & $65.22^{\circ}-65.35^{\circ}$ & $0.496 \pm 0.0059$ & $0.421 \pm 0.0196$ \\
\hline 1.270 & 0.020 & 410.52 & $65.22^{\circ}-65.35^{\circ}$ & $0.399 \pm 0.0056$ & $0.342 \pm 0.0166$ \\
\hline 2.200 & 0.040 & 82.693 & $65.22^{\circ}-65.27^{\circ}$ & 0.199 & $0.137 \pm 0.0132$ \\
\hline \multicolumn{6}{|c|}{ (C) Melt-season sea ice (June 5, 1995) } \\
\hline 0.472 & 0.021 & 1962.9 & $54.51^{\circ}-55.26^{\circ}$ & $0.737 \pm 0.0061$ & $0.696 \pm 0.0813$ \\
\hline 0.675 & 0.020 & 1471.7 & $54.51^{\circ}-55.26^{\circ}$ & $0.666 \pm 0.0023$ & $0.626 \pm 0.0852$ \\
\hline 0.869 & 0.022 & 943.60 & $54.51^{\circ}-55.26^{\circ}$ & $0.581 \pm 0.0024$ & $0.519 \pm 0.0772$ \\
\hline 1.038 & 0.020 & 671.13 & $54.51^{\circ}-55.26^{\circ}$ & $0.379 \pm 0.0023$ & $0.298 \pm 0.0427$ \\
\hline 1.219 & 0.020 & 475.07 & $54.51^{\circ}-55.26^{\circ}$ & $0.189 \pm 0.0025$ & $0.130 \pm 0.0194$ \\
\hline 1.271 & 0.021 & 430.81 & $54.51^{\circ}-55.26^{\circ}$ & $0.175 \pm 0.0021$ & $0.119 \pm 0.0188$ \\
\hline 1.643 & 0.041 & 229.64 & $54.86^{\circ}-55.26^{\circ}$ & $0.032 \pm 0.0022$ & $0.019 \pm 0.0085$ \\
\hline 2.207 & 0.040 & 72.250 & $54.51^{\circ}-54.69^{\circ}$ & 0.034 & $0.020 \pm 0.0132$ \\
\hline \multicolumn{6}{|c|}{ (D) Melt-season sea ice (June 8, 1995) } \\
\hline 0.472 & 0.021 & 1961.8 & $53.28^{\circ}-57.69^{\circ}$ & $0.734 \pm 0.0191$ & $0.689 \pm 0.1367$ \\
\hline 0.675 & 0.020 & 1471.0 & $53.28^{\circ}-57.69^{\circ}$ & $0.640 \pm 0.0192$ & $0.592 \pm 0.1293$ \\
\hline 0.869 & 0.022 & 943.11 & $53.28^{\circ}-57.69^{\circ}$ & $0.538 \pm 0.0178$ & $0.470 \pm 0.1157$ \\
\hline 1.038 & 0.020 & 670.79 & $53.28^{\circ}-57.69^{\circ}$ & $0.341 \pm 0.0128$ & $0.265 \pm 0.0684$ \\
\hline 1.219 & 0.021 & 474.83 & $53.28^{\circ}-57.69^{\circ}$ & $0.170 \pm 0.0097$ & $0.117 \pm 0.0305$ \\
\hline 1.271 & 0.020 & 430.58 & $53.28^{\circ}-57.69^{\circ}$ & $0.156 \pm 0.0092$ & $0.105 \pm 0.0274$ \\
\hline 1.643 & 0.041 & 229.52 & $55.19^{\circ}-57.69^{\circ}$ & $0.031 \pm 0.0020$ & $0.016 \pm 0.0089$ \\
\hline 2.207 & 0.040 & 72.210 & $54.41^{\circ}-56.72^{\circ}$ & $0.031 \pm 0.0024$ & $0.019 \pm 0.0128$ \\
\hline \multicolumn{6}{|c|}{ (E) Melt-season sea ice (June 8,1995 ) } \\
\hline 0.472 & 0.021 & 1961.8 & $48.93^{\circ}-49.45^{\circ}$ & $0.707 \pm 0.0080$ & $0.679 \pm 0.0996$ \\
\hline 0.675 & 0.020 & 1471.0 & $48.93^{\circ}-49.45^{\circ}$ & $0.619 \pm 0.0110$ & $0.592 \pm 0.1100$ \\
\hline 0.869 & 0.022 & 943.11 & $48.93^{\circ}-49.45^{\circ}$ & $0.511 \pm 0.0105$ & $0.465 \pm 0.1117$ \\
\hline 1.038 & 0.020 & 670.79 & $48.93^{\circ}-49.45^{\circ}$ & $0.319 \pm 0.0068$ & $0.259 \pm 0.0615$ \\
\hline 1.219 & 0.021 & 474.83 & $48.93^{\circ}-49.45^{\circ}$ & $0.154 \pm 0.0039$ & $0.109 \pm 0.0251$ \\
\hline 1.271 & 0.020 & 430.58 & $48.93^{\circ}-49.45^{\circ}$ & $0.145 \pm 0.0040$ & $0.101 \pm 0.0232$ \\
\hline 1.643 & 0.041 & 229.52 & $49.22^{\circ}-49.45^{\circ}$ & $0.028 \pm 0.0025$ & $0.016 \pm 0.0075$ \\
\hline 2.207 & 0.040 & 72.210 & $48.97^{\circ}-49.12^{\circ}$ & $0.025 \pm 0.0013$ & $0.017 \pm 0.0111$ \\
\hline
\end{tabular}


Table 3. Computed spectral albedo and measured nadir reflectance for snowcovered tundra $(F)$ and snow-free tundra $(G, H)$. Uncertainties do not include possible errors in calibration.

\begin{tabular}{|c|c|c|c|c|c|}
\hline $\begin{array}{c}\text { Central wave- } \\
\text { length }(\mu \mathrm{m})\end{array}$ & $\begin{array}{c}\text { Bandwidth } \\
(\mu \mathrm{m})\end{array}$ & $\begin{array}{c}\text { Solar flux } \\
\left(\mathrm{W} \mathrm{m}^{-2} \mu^{-1}\right)\end{array}$ & Solar zenith angle & Albedo & Nadir reflectance \\
\hline \multicolumn{6}{|c|}{ (F) Snow-covered tundra (April 7, 1992) } \\
\hline 0.503 & 0.016 & 1901.7 & $65.14^{\circ}-65.35^{\circ}$ & $0.698 \pm 0.0141$ & $0.663 \pm 0.0253$ \\
\hline 0.673 & 0.020 & 1523.5 & $65.14^{\circ}-65.35^{\circ}$ & $0.725 \pm 0.0189$ & $0.698 \pm 0.0338$ \\
\hline 0.754 & 0.019 & 1281.1 & $65.14^{\circ}-65.35^{\circ}$ & $0.770 \pm 0.0214$ & $0.755 \pm 0.0376$ \\
\hline 0.866 & 0.020 & 947.85 & $65.14^{\circ}-65.35^{\circ}$ & $0.732 \pm 0.0218$ & $0.699 \pm 0.0395$ \\
\hline 1.031 & 0.020 & 706.75 & $65.14^{\circ}-65.35^{\circ}$ & $0.659 \pm 0.0221$ & $0.606 \pm 0.0403$ \\
\hline 1.220 & 0.021 & 497.66 & $65.14^{\circ}-65.35^{\circ}$ & $0.462 \pm 0.0181$ & $0.402 \pm 0.0295$ \\
\hline 1.270 & 0.020 & 410.52 & $65.14^{\circ}-65.35^{\circ}$ & $0.379 \pm 0.0146$ & $0.330 \pm 0.0256$ \\
\hline 1.640 & 0.040 & 232.27 & $65.14^{\circ}-65.24^{\circ}$ & 0.156 & $0.104 \pm 0.0126$ \\
\hline \multicolumn{6}{|c|}{ (G) Tundra - no snow (June 12,1995 ) } \\
\hline 0.472 & 0.021 & 1962.9 & $80.63^{\circ}-81.23^{\circ}$ & $0.053 \pm 0.0006$ & $0.027 \pm 0.0070$ \\
\hline 0.675 & 0.020 & 1471.7 & $80.63^{\circ}-81.23^{\circ}$ & $0.105 \pm 0.0017$ & $0.060 \pm 0.0117$ \\
\hline 0.869 & 0.020 & 943.60 & $80.63^{\circ}-81.23^{\circ}$ & $0.266 \pm 0.0041$ & $0.174 \pm 0.0249$ \\
\hline 1.038 & 0.020 & 671.13 & $80.63^{\circ}-81.23^{\circ}$ & $0.345 \pm 0.0054$ & $0.228 \pm 0.0343$ \\
\hline 1.219 & 0.021 & 475.07 & $80.63^{\circ}-81.23^{\circ}$ & $0.318 \pm 0.0047$ & $0.214 \pm 0.0335$ \\
\hline 1.271 & 0.020 & 430.81 & $80.63^{\circ}-81.23^{\circ}$ & $0.271 \pm 0.0038$ & $0.187 \pm 0.0301$ \\
\hline 1.643 & 0.041 & 229.64 & $80.63^{\circ}-80.98^{\circ}$ & $0.334 \pm 0.0187$ & $0.209 \pm 0.0428$ \\
\hline 2.100 & 0.039 & 92.280 & $81.12^{\circ}-81.23^{\circ}$ & 0.197 & $0.121 \pm 0.0370$ \\
\hline \multicolumn{6}{|c|}{ (H) Tundra - no snow (June 12,1995 ) } \\
\hline 0.472 & 0.021 & 1962.9 & $82.00^{\circ}-82.61^{\circ}$ & $0.053 \pm 0.0026$ & $0.027 \pm 0.0231$ \\
\hline 0.675 & 0.020 & 1471.7 & $82.00^{\circ}-82.61^{\circ}$ & $0.096 \pm 0.0016$ & $0.056 \pm 0.0292$ \\
\hline 0.869 & 0.020 & 943.60 & $82.00^{\circ}-82.61^{\circ}$ & $0.260 \pm 0.0007$ & $0.179 \pm 0.0378$ \\
\hline 1.038 & 0.020 & 671.13 & $82.00^{\circ}-82.61^{\circ}$ & $0.331 \pm 0.0015$ & $0.231 \pm 0.0479$ \\
\hline 1.219 & 0.021 & 475.07 & $82.00^{\circ}-82.61^{\circ}$ & $0.298 \pm 0.0025$ & $0.211 \pm 0.0420$ \\
\hline 1.271 & $0.02 n$ & 430.81 & $82.00^{\circ}-82.61^{\circ}$ & $0.244 \pm 0.0008$ & $0.176 \pm 0.0367$ \\
\hline 1.643 & 0.041 & 229.64 & $82.00^{\circ}-82.26^{\circ}$ & $0.328 \pm 0.0054$ & $0.241 \pm 0.0412$ \\
\hline 2.100 & 0.039 & 92.280 & $82.38^{\circ}-82.61^{\circ}$ & $0.191 \pm 0.0002$ & $0.128 \pm 0.0461$ \\
\hline
\end{tabular}




\section{FIGURE LEGENDS}

Figure 1. Approximate location of each set of sea ice and tundra BRF measurements.

Figure 2. Sample photos of each of the four surface types measured: (a) snowcovered sea ice; (b) melt-season sea ice; (c) snow-covered tundra (Trans-Alaska Pipeline and road in upper right corner of photo); and (d) tundra shortly after snow melt. Photos a-c were taken from the University of Washington C-131A aircraft, whereas photo d was taken from the ground. Photos by Michael D. King.

Figure 3. Spectral measurements of surface-atmosphere bidirectional reflectance over snow-covered sea ice on April 7, 1992 during LEADEX. All bands are from BRF A (see figure 1) except i $(2.2 \mu \mathrm{m})$ which is from BRF B. The location of the anti-solar point at $\theta=65^{\circ}$ and $\phi=180^{\circ}$ is indicated in figure $3 a$.

Figure 4. Representative angular distribution of BRF in the principal plane for (a) the snow-covered and (b) melt-season sea ice surfaces. The capital letter after each channel label denotes from which BRF the principal plane plot was derived.

Figure 5. Spectral measurements of surface-atmosphere bidirectional reflectance over melt-season sea ice. This case is BRF D from June 8, 1995 during ARMCAS, but is representative of the other two melt-season sea ice cases. The location of the anti-solar point at $\theta=55^{\circ}$ and $\phi=180^{\circ}$ is indicated in figure $5 \mathrm{a}$.

Figure 6. Spectral measurements of surface-atmosphere bidirectional reflectance over snow-covered tundra. This case is from BRF F from April 7, 1992 during LEADEX. The location of the anti-solar point at $\theta=65^{\circ}$ and $\phi=$ 
$180^{\circ}$ is indicated in figure $6 \mathrm{a}$.

Figure 7. Representative angular distribution of BRF in the principal plane for the (a) snow-covered and (b) snow-free tundra surfaces. The capital letter after each channel label denotes from which BRF the principal plane plot was derived.

Figure 8. Spectral measurements of surface-atmosphere bidirectional reflectance over snow- free tundra. This case is BRF G on June 12, 1995 during ARMCAS. The location of the anti-solar point at $\theta=81^{\circ}$ and $\phi=180^{\circ}$ is indicated in figure 8 .

Figure 9. Hemispherical albedo, nadir reflectance, and ratio of nadir reflectance to albedo plotted as a function of wavelength for BRFs A-H. The dashed lines represent the effect of adding a Rayleigh scattering and ozone absorption correction to the data (for clarity shown only for BRFs $A, D, F$, and $G$ ). 
Arnold et al.: Surface-Atmosphere Anisotropy of Sea Ice and Tundra

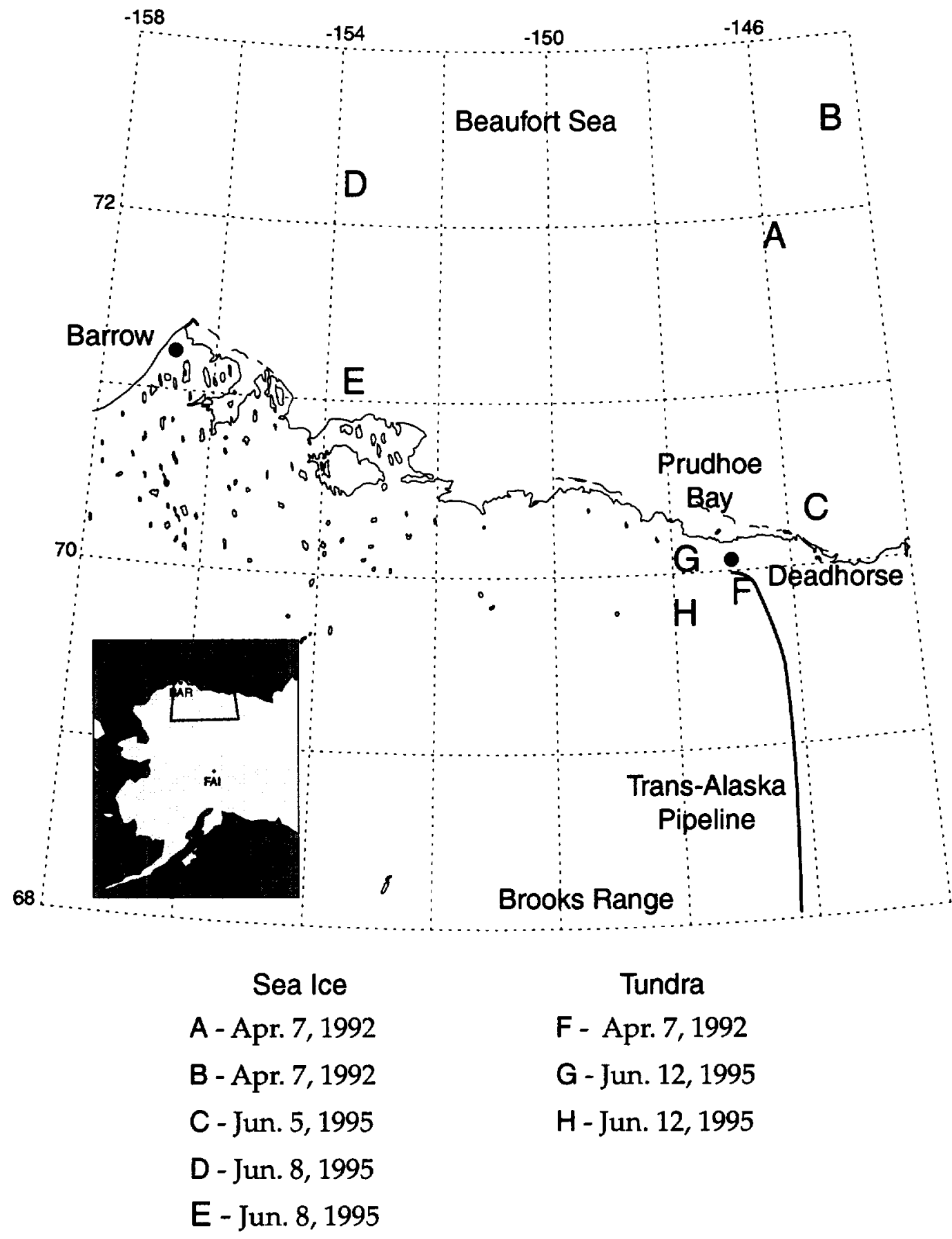

Figure 1. Approximate location of each set of sea ice and tundra BRF measurements. 
a)

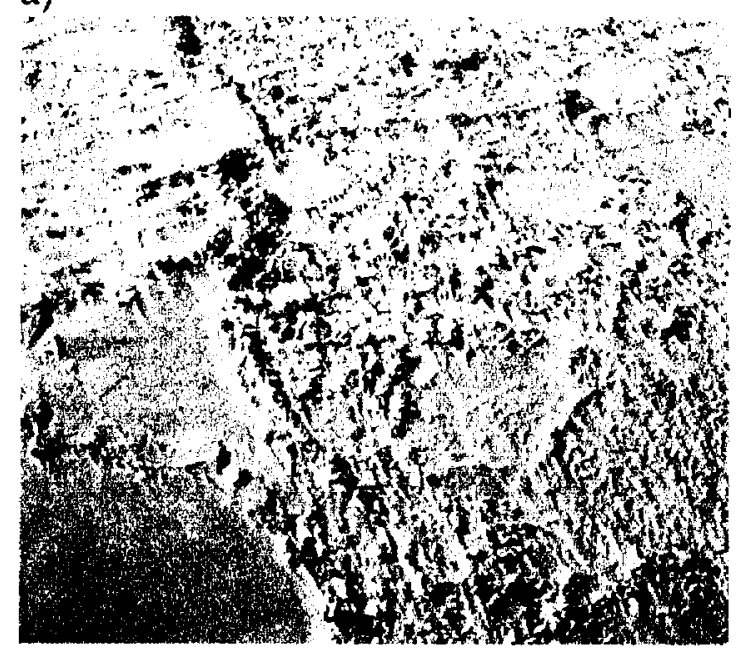

c)

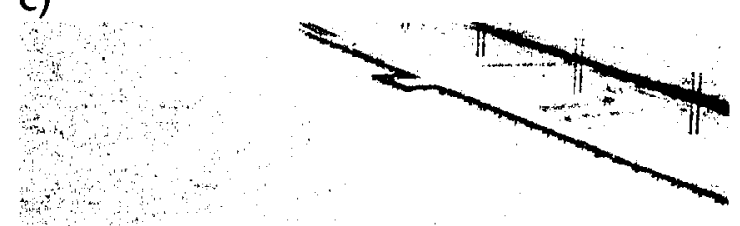

b)

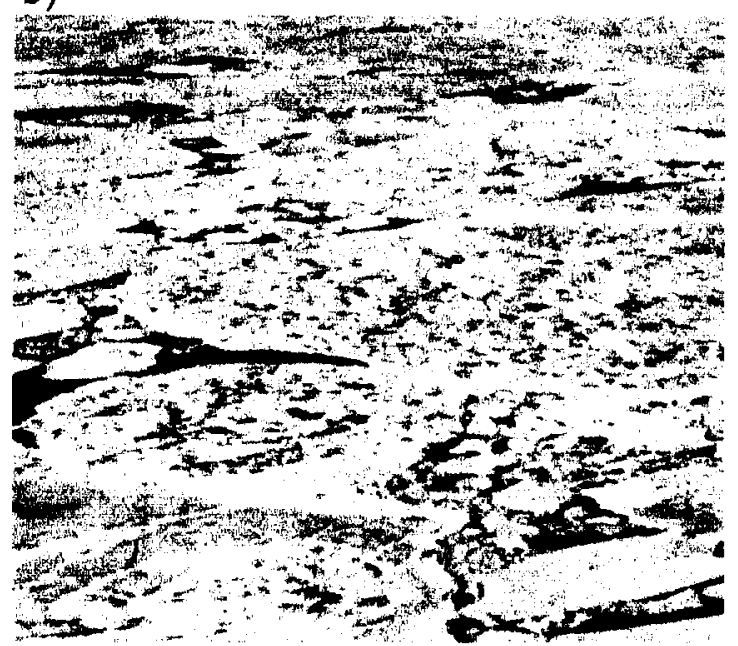

d)

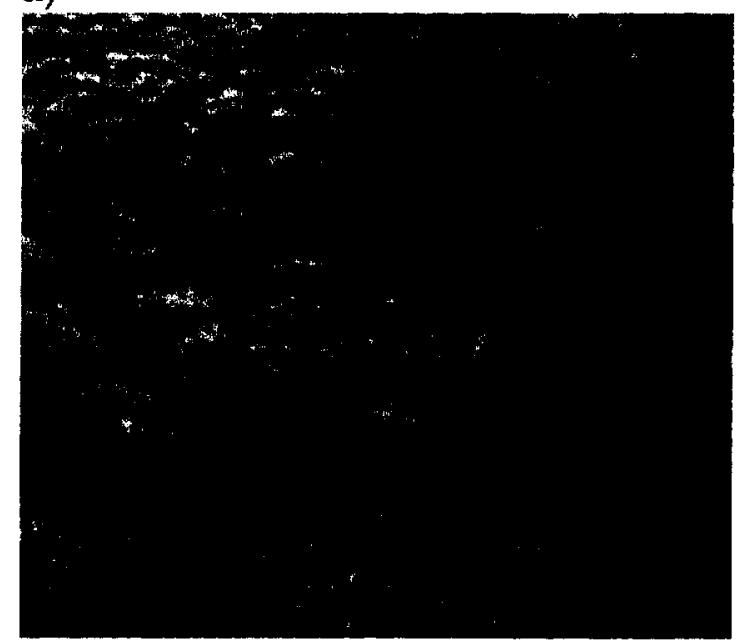

Figure 2. Sample photos of each of the four surface types measured: (a) snowcovered sea ice; (b) melt-season sea ice; (c) snow-covered tundra (Trans-Alaska Pipeline and road in upper right corner of photo); and (d) tundra shortly after snow melt. Photos a-c were taken from the University of Washington C-131A aircraft, whereas photo $\mathrm{d}$ was taken from the ground. Photos by Michael D. King. 
(a) $0.503 \mu \mathrm{m}$

(c) $0.754 \mu \mathrm{m}$

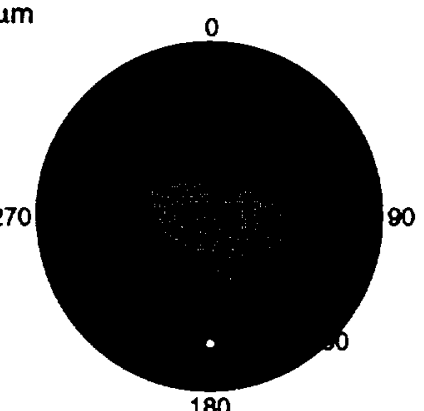

(e) $1.031 \mu \mathrm{m}$

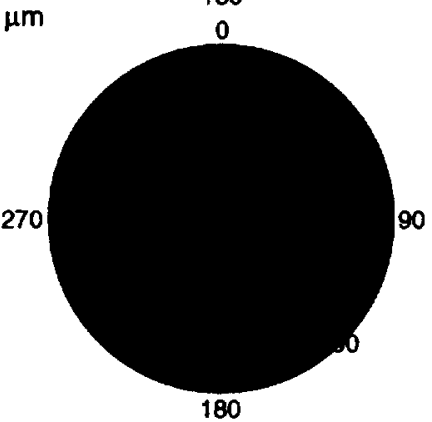

(g) $1.270 \mu \mathrm{m}$
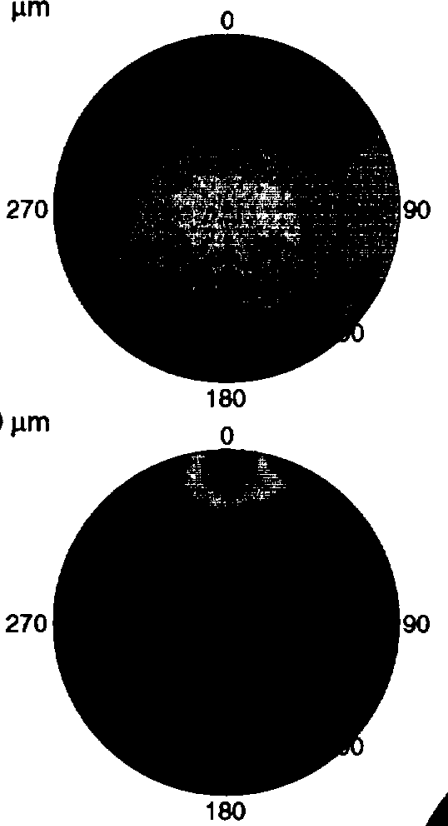

(b) $0.673 \mu \mathrm{m}$

(d) $0.866 \mu \mathrm{m}$

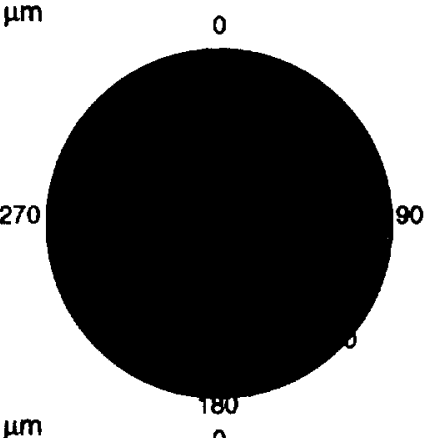

(f) $1.220 \mu \mathrm{m}$
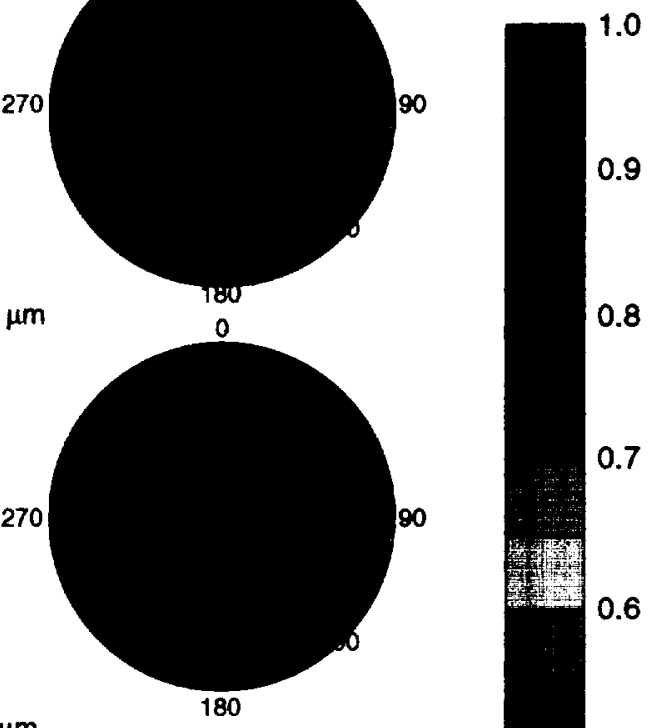

0.8

0.7

(h) $1.640 \mu \mathrm{m}$

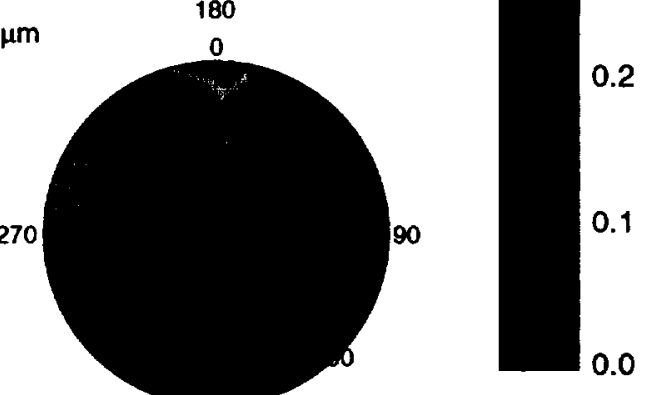

Figure 3. Spectral measurements of surface-atmosphere bidirectional reflectance over snow-covered sea ice on April 7, 1992 during LEADEX. All bands are from BRF A (see figure 1) except i $(2.2 \mu \mathrm{m})$ which is from BRF B. The location of the anti-solar point at $\theta=65^{\circ}$ and $\phi=180^{\circ}$ is indicated in figure $3 a$. 
a) Snow-Covered Sea Ice $\left(\theta_{0}=65^{\circ}\right)$
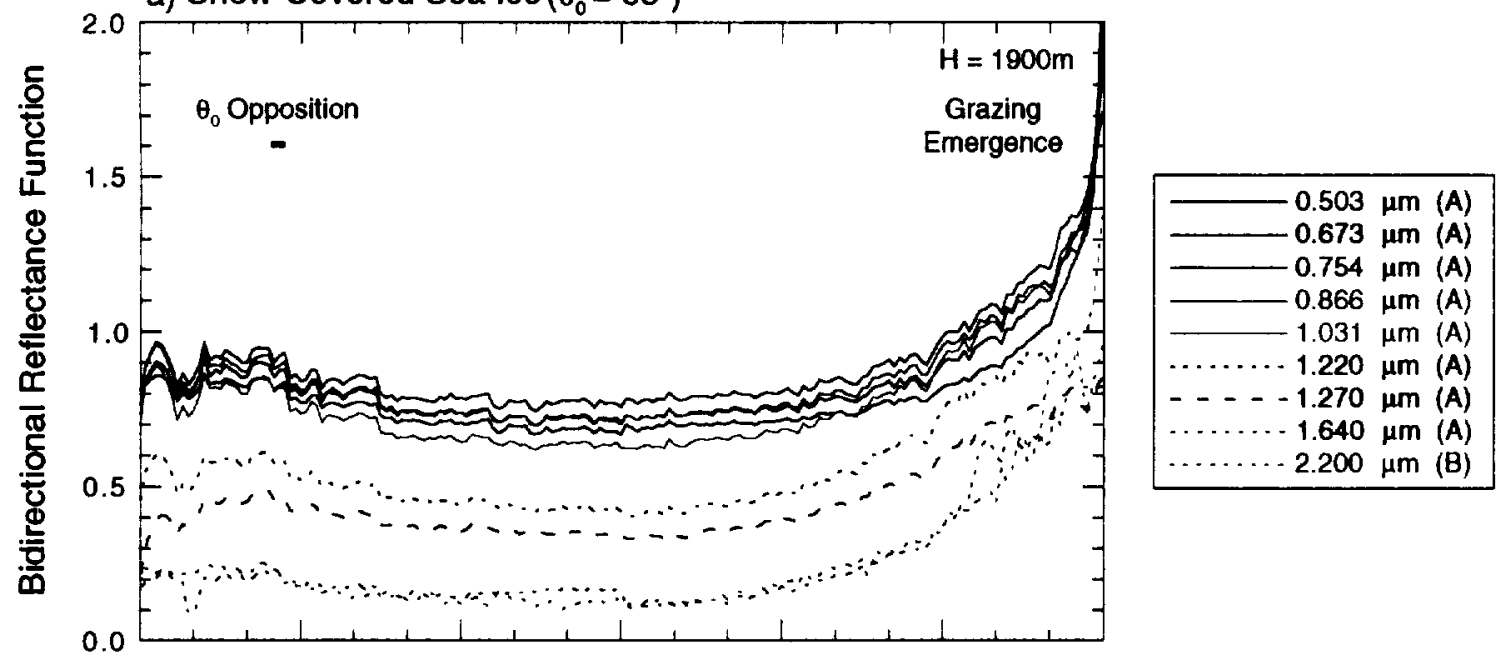

b) Melt-Season Sea Ice $\left(\theta_{0}=54^{\circ}\right)$

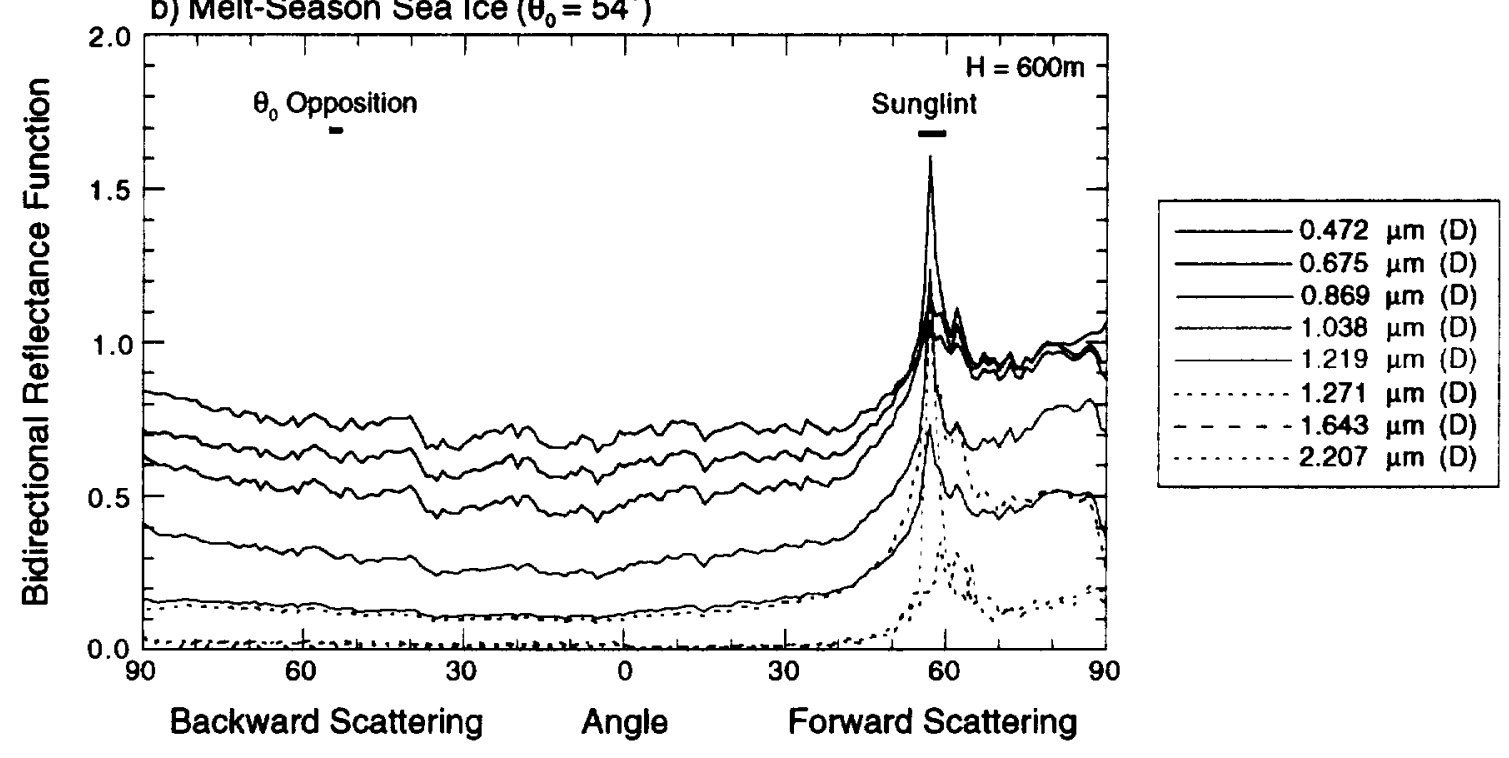

Figure 4. Representative angular distribution of BRF in the principal plane for (a) the snow-covered and (b) melt-season sea ice surfaces. The capital letter after each channel label denotes from which BRF the principal plane plot was derived. 
(a) $0.473 \mu \mathrm{m}$

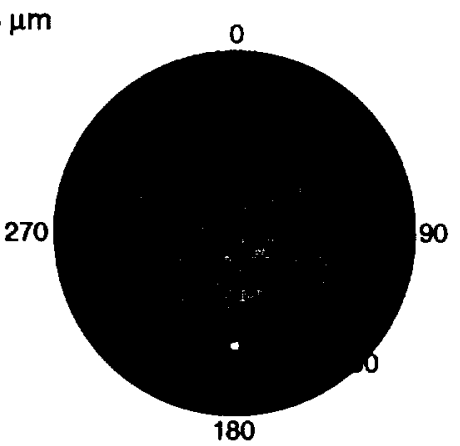

(c) $0.869 \mu \mathrm{m}$

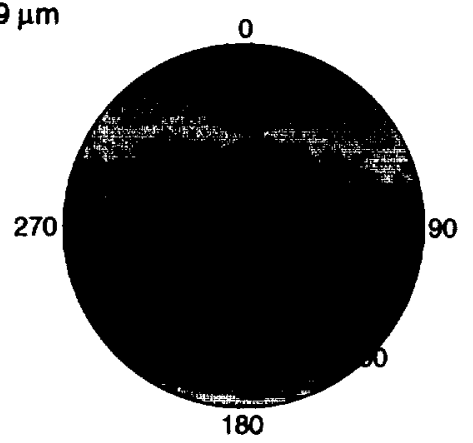

(e) $1.219 \mu \mathrm{m}$

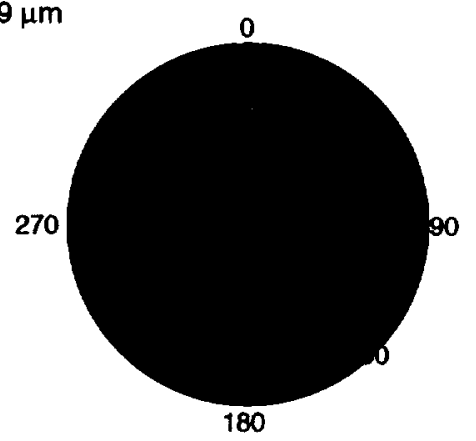

(g) $1.643 \mu \mathrm{m}$

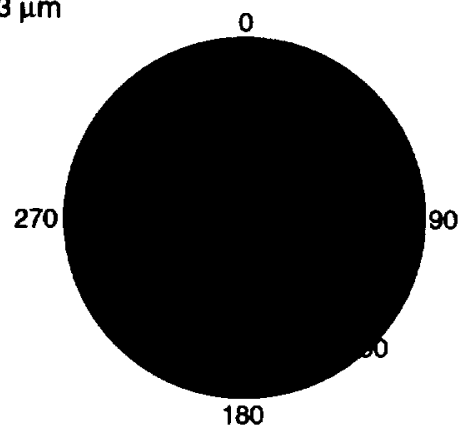

(b) $0.675 \mu \mathrm{m}$

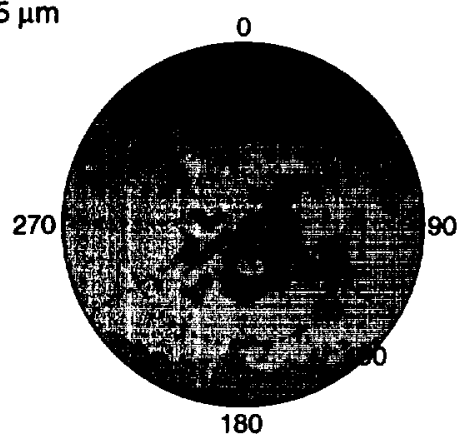

(d) $1.038 \mu \mathrm{m}$

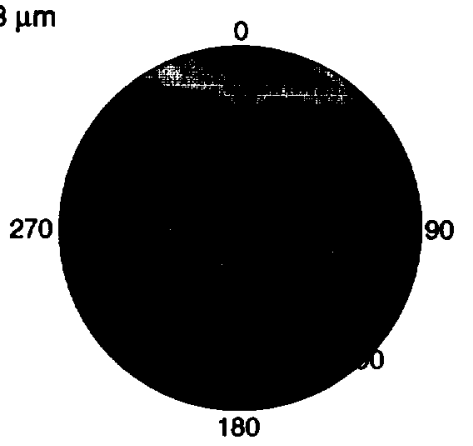

(f) $1.271 \mu \mathrm{m}$

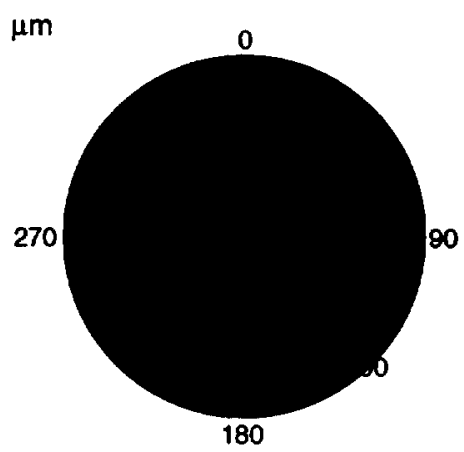

(h) $2.200 \mu \mathrm{m}$

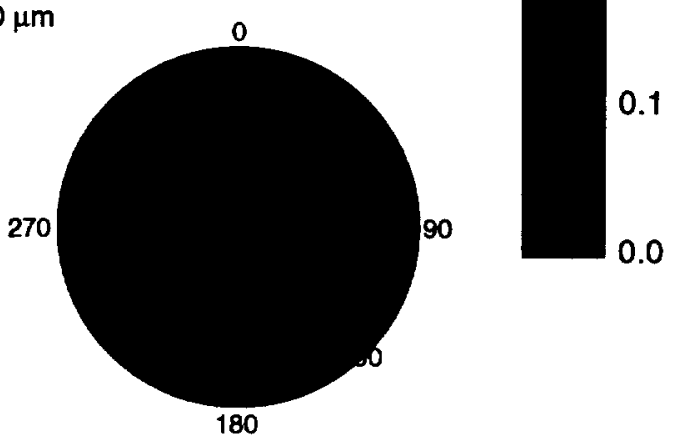

Figure 5. Spectral measurements of surface-atmosphere bidirectional reflectance over melt-season sea ice. This case is BRF D from June 8, 1995 during ARMCAS, but is representative of the other two melt-season sea ice cases. The location of the anti-solar point at $\theta=55^{\circ}$ and $\phi=180^{\circ}$ is indicated in figure $5 \mathrm{a}$. 
(a) $0.503 \mu \mathrm{m}$

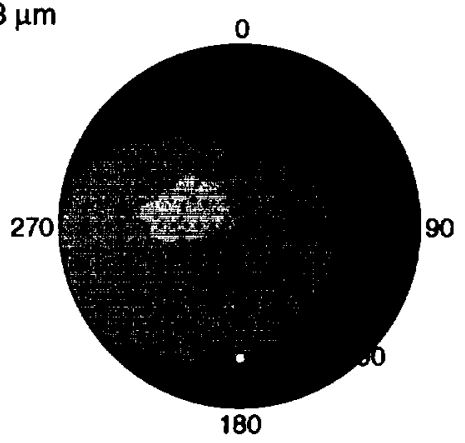

(c) $0.754 \mu \mathrm{m}$

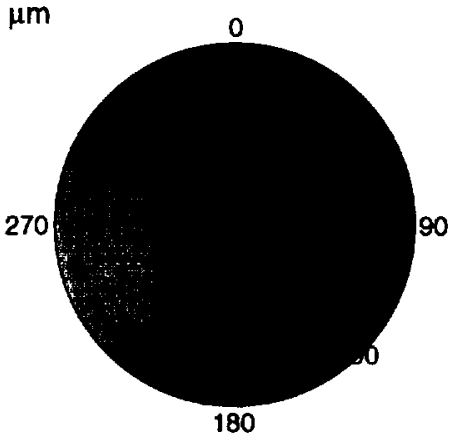

(e) $1.031 \mu \mathrm{m}$

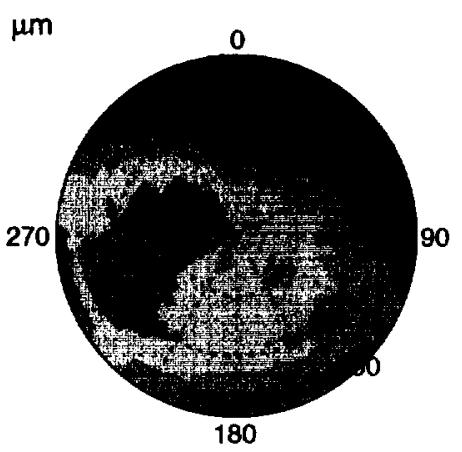

(g) $1.270 \mu \mathrm{m}$

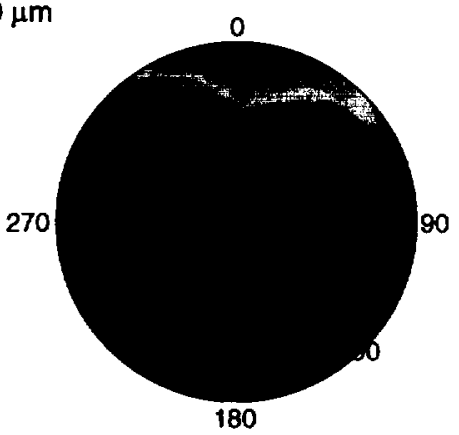

(b) $0.673 \mu \mathrm{m}$

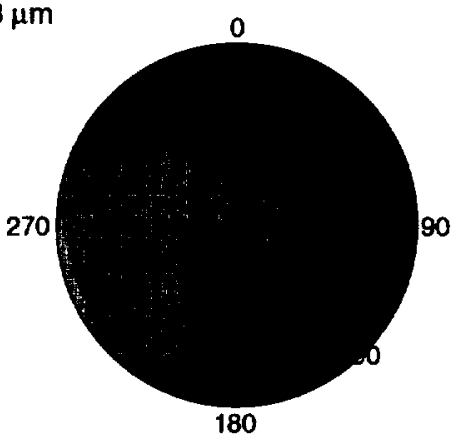

(d) $0.866 \mu \mathrm{m}$

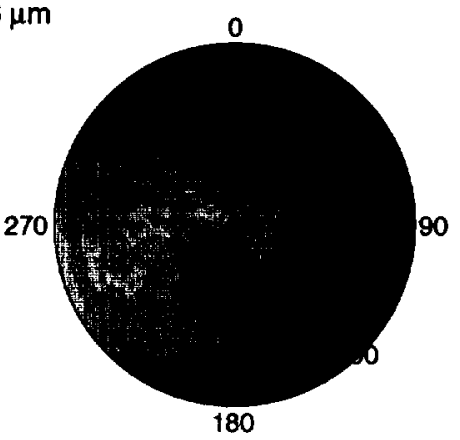

(f) $1.220 \mu \mathrm{m}$

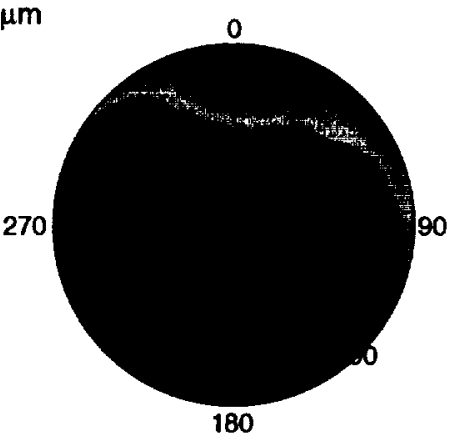

(h) $1.640 \mu \mathrm{m}$

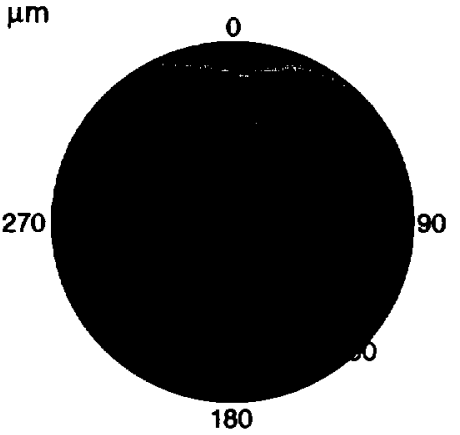

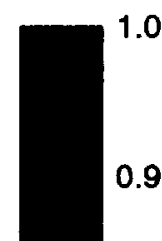

0.8

0.7

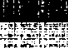

0.6

0.5

0.4

0.3

0.2

0.1

0.0

Figure 6. Spectral measurements of surface-atmosphere bidirectional reflectance over snow-covered tundra. This case is from BRF F from April 7, 1992 during LEADEX. The location of the anti-solar point at $\theta=65^{\circ}$ and $\phi=$ $180^{\circ}$ is indicated in figure $6 \mathrm{a}$. 

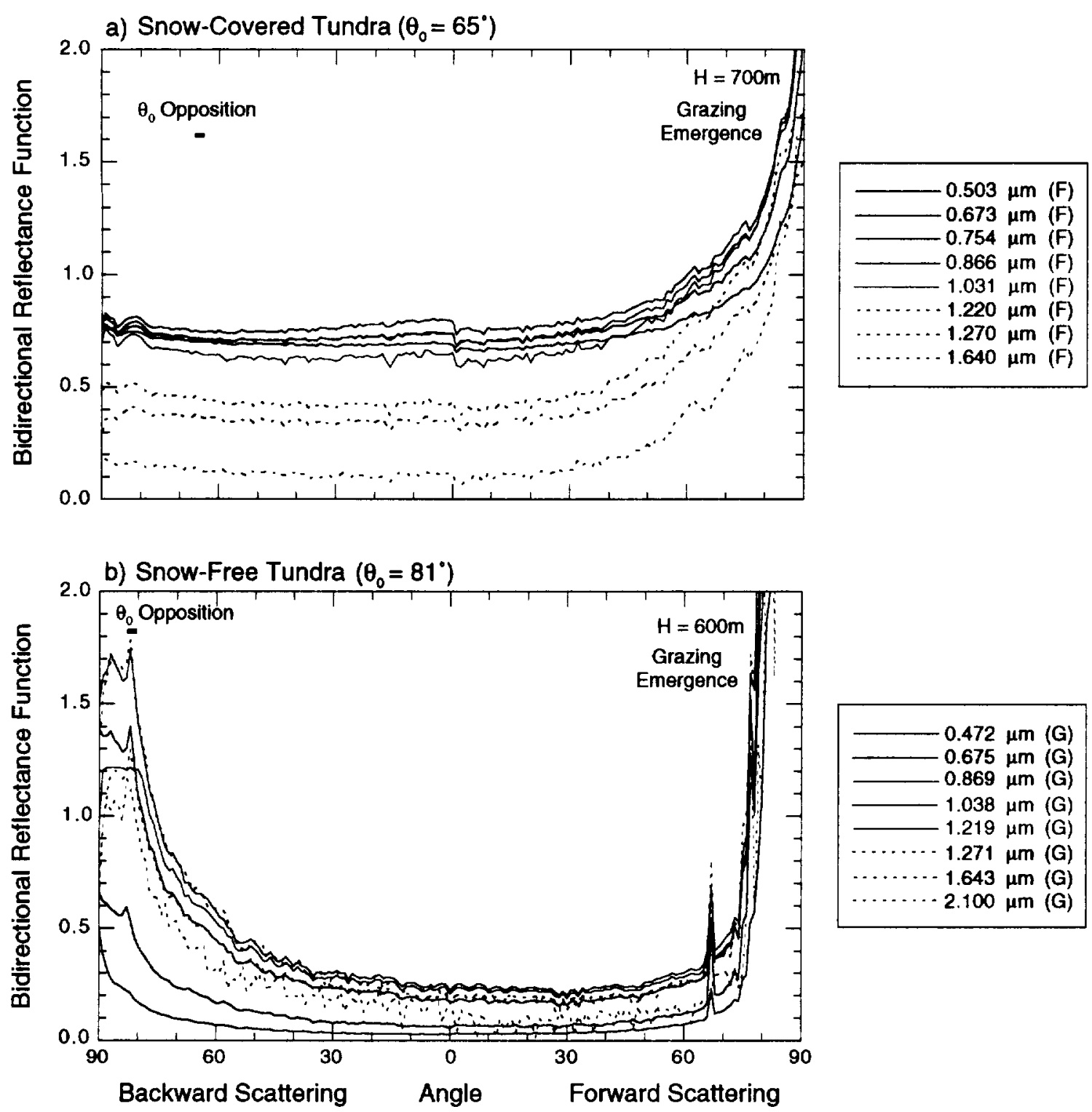

Figure 7. Representative angular distribution of BRF in the principal plane for the (a) snow-covered and (b) snow-free tundra surfaces. The capital letter after each channel label denotes from which BRF the principal plane plot was derived. 
(a) $0.472 \mu \mathrm{m}$

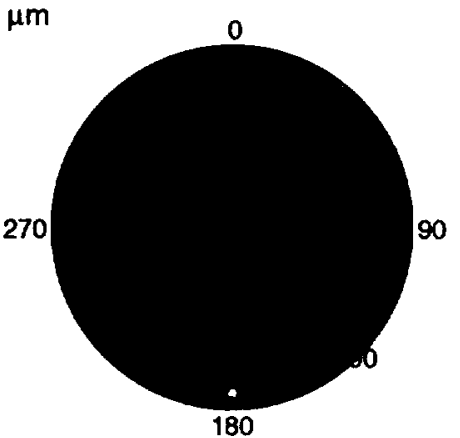

(c) $0.869 \mu \mathrm{m}$

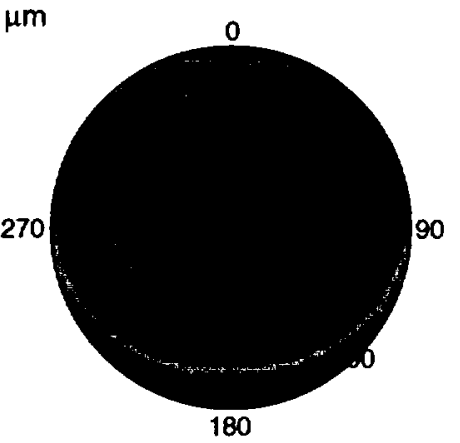

(e) $1.219 \mu \mathrm{m}$

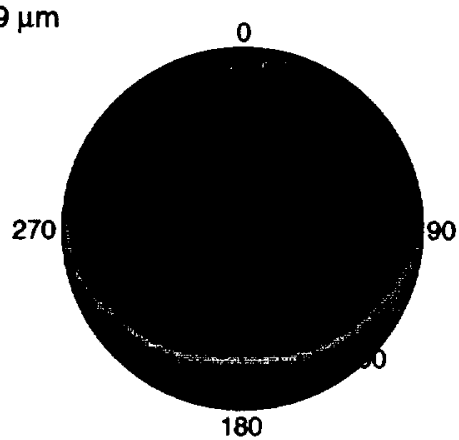

(g) $1.643 \mu \mathrm{m}$

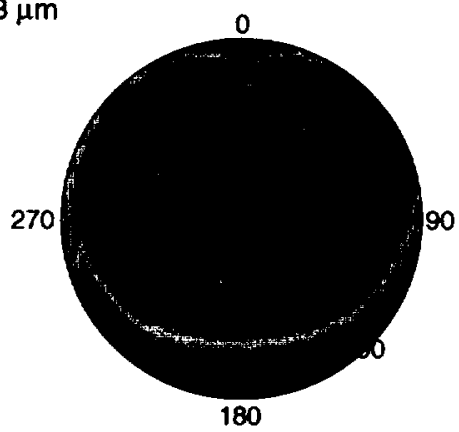

(b) $0.675 \mu \mathrm{m}$

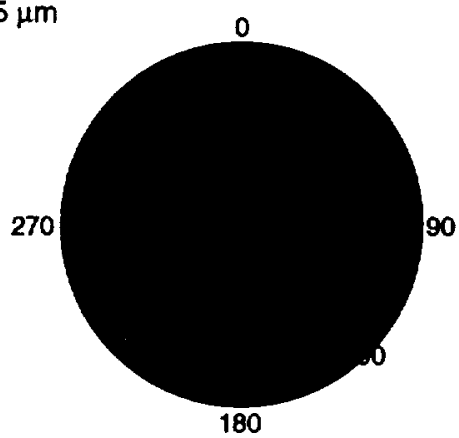

(d) $1.038 \mu \mathrm{m}$

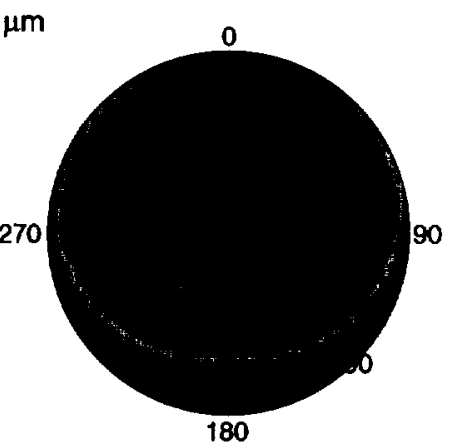

(f) $1.271 \mu \mathrm{m}$

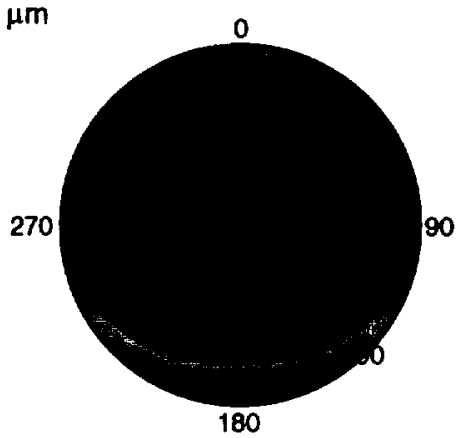

(h) $2.100 \mu \mathrm{m}$

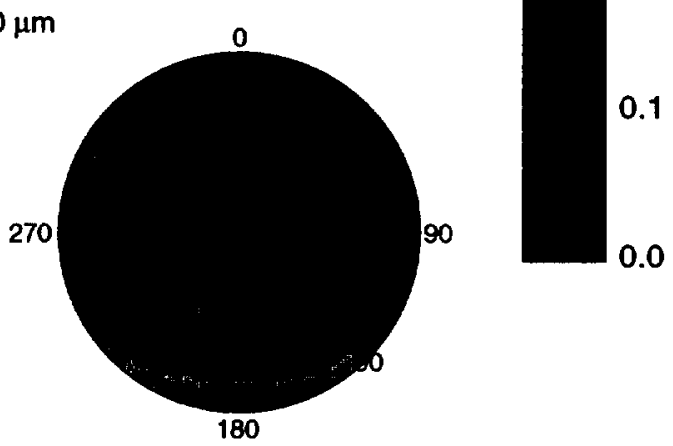

Figure 8. Spectral measurements of surface-atmosphere bidirectional reflectance over snow- free tundra. This case is BRF G on June 12, 1995 during ARMCAS. The location of the anti-solar point at $\theta=81^{\circ}$ and $\phi=180^{\circ}$ is indicated in figure 8 . 

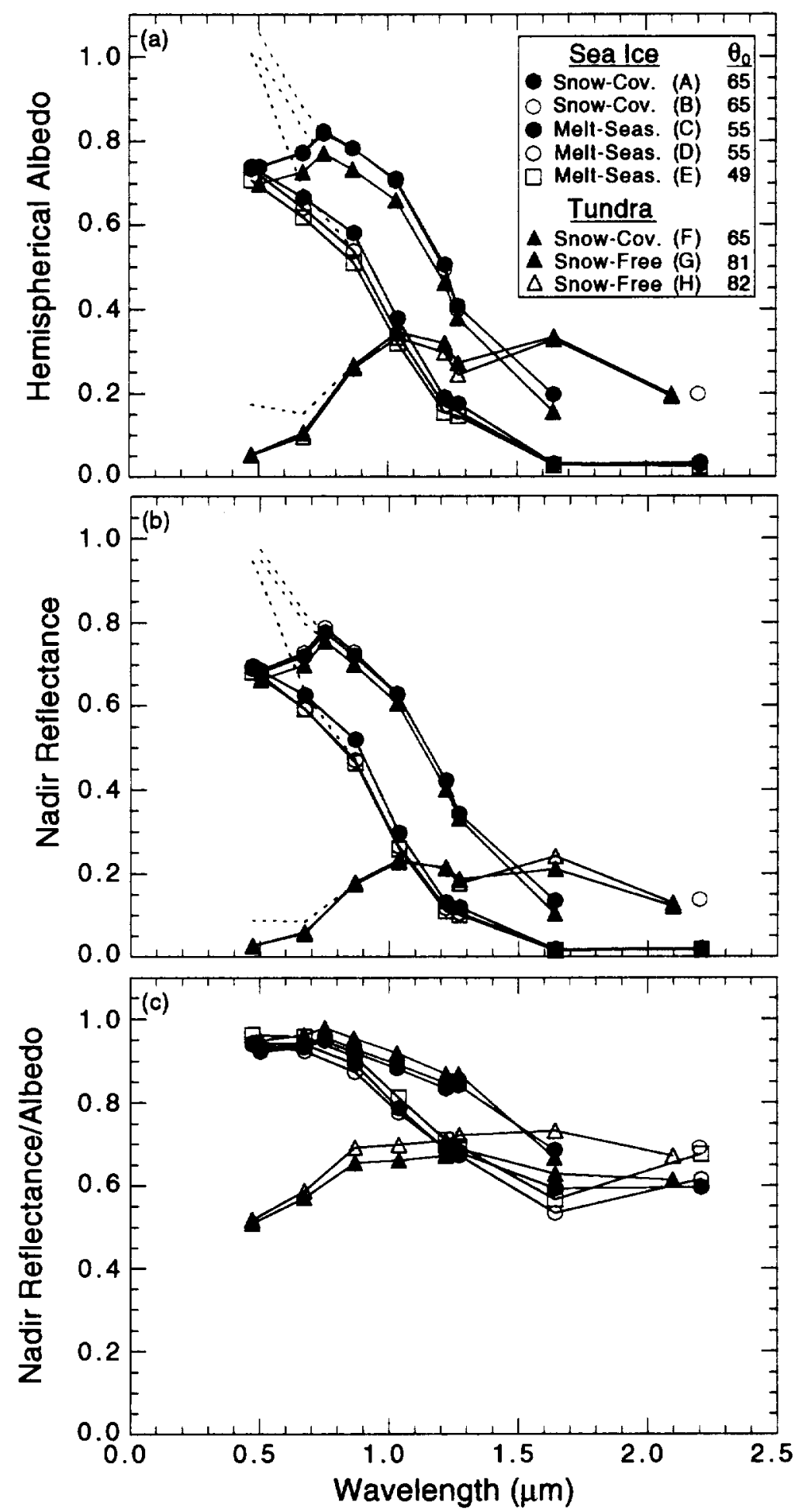

Figure 9. Hemispherical albedo, nadir reflectance, and ratio of nadir reflectance to albedo plotted as a function of wavelength for BRFs A-H. The dashed lines represent the effect of adding a Rayleigh scattering and ozone absorption correction to the data (for clarity shown only for BRFs $A, D, F$, and $G$ ). 